\title{
EFFECT OF $\alpha$-TOCOPHEROL ON PRO-OXIDANT AND ANTIOXIDANT ENZYME STATUS IN RADIATION-TREATED ORAL SQUAMOUS CELL CARCINOMA
}

S. CHITRA, C. S. SHYAMALA DEVI

\section{ABSTRACT}

OBJ ECTIVES: The relationships between $\mathbf{a}$-tocopherol, pro-oxidant and antioxidant enzyme status, and radiation toxicity were studied in stage II, III, and IVA oral squamous cell carcinoma patients. The low levels of malondialdehyde and increased activities of antioxidant enzymes were correlated with decreased oxidative stress by $\boldsymbol{a}$-tocopherol in oral cancer patients treated with radiotherapy. The objective of the present study was to evaluate the effect of a-tocopherol on oxidant-antioxidant enzyme status in oral squamous cell carcinoma patients treated with radiotherapy. MATERIALS AND METHODS: The study included three groups with histologically confirmed oral squamous cell carcinoma patients (untreated), and they were further divided into two groups, viz., one consisting of patients who underwent radiotherapy alone (radiotherapy was given at the dosage of $6000 \mathrm{cGy}$ in five fractions per week for a period of 6 weeks); and the other group treated with radiotherapy plus a-tocopherol supplementation (a-tocopherol was supplemented at a dosage of $400 \mathrm{IU} /$ day) for the entire period of radiotherapy. RESULTS: A significant decrease $(P<0.001)$ in malondialdehyde levels and increase in activities of antioxidant enzymes $(P<0.001)$ in hemolysate were noticed in patients treated with radiotherapy and simultaneously supplemented with a-tocopherol when compared to radiation-treated patients. CONCLUSION: It was seen that $\mathbf{a}$-tocopherol played a role in protecting against the damage caused by irradiation in oral squamous cell carcinoma patients treated with radiotherapy, by enhancing the antioxidant enzyme status and reducing the pro-oxidant status.

Key words: Glutathione-dependent enzymes, malondialdehyde, oral squamous cell carcinoma, radiotherapy, superoxide dismutase, $\mathbf{a}$-tocopherol

\section{INTRODUCTION}

Radiation therapy (RT) is the most commonly College of Biomedical Sciences, Technology and Research, Sri Ramachandra University, Porur, 1Department of Biochemistry and Molecular Biology, University of Madras, Chennai, India

\section{Correspondence:}

Dr. S. Chitra, College of Biomedical Sciences, Technology and Research, Sri Ramachandra University, OP Block: IVth Floor, Porur, Chennai - 600 116, India. used therapeutic modality in the treatment of oral cancer. Free radical-induced cellular damages have been implicated in many patho-biological conditions, malignancy, aging process, degenerative diseases, etc. ${ }^{[1]}$ Tumor cells are readily killed by heat than are normal cells, especially, erythrocytic precursors are more heat sensitive than the granulocytic precursor. ${ }^{[2]}$ Exposure to ionizing radiation has been reported to induce hyperthermia in cats, rabbits, ${ }^{[3]}$ and humans. ${ }^{[4]}$ Glutathione peroxidase (GPx) protects aerobic cells against oxygen toxicity and lipid peroxidation. Glutathione (GSH) acts as a substrate or cofactor for the antioxidant enzymes GPx; glutathione-Stransferase (GST); and glutathione reductase (GR), which is involved in the termination of peroxidation. In addition, cancer patients may also face a number of side effects from their radiation treatment, including fatigue, skin problems, loss of appetite, and also some biochemical complications like damage to the macromolecules such as DNA, protein, and membrane phospholipids. Supplementation is essential to reduce the toxicity during $\mathrm{RT}$ in ora cancer. Our previous study also suggested that an antioxidant supplementation can improve the antioxidant enzyme activity in radiationtreated oral cancer patients. ${ }^{[5]}$ a-tocopherol, a free-radical scavenger and chain-breaking antioxidant, has been taken for the present study to reduce the adverse effects during radiotherapy in oral squamous cell carcinoma (OSCC) patients. Its structural role, membranestabilizing effects, and protective action on membrane lipids and unsaturated fatty acids against oxidative degradation have been reported. ${ }^{[6]}$ The aim of our present investigation was to evaluate the relationship between a-tocopherol and radiation toxicity, as well as the effect of a-tocopherol on oxidant and antioxidant enzymes in OSSC patients.

\section{MATERIALS AND METHODS}

Blood samples were collected from histologically confirmed patients between 1999 and 2001, prospectively from 79 consecutive consenting patients presenting at the Government Arigna Anna Memorial Cancer Research Institute and
Hospital, Kancheepuram, Tamil Nadu, India, and included in this cancer clinical trial. These 79 patients with OSCC (mean \pm SD $=50 \pm 12$ years) comprised of 47 males and 32 females. OSCC patients had cancer at various sites such as the cheek $(n=24)$, tongue $(n=15)$, alveolus $(n=13)$, floor of the mouth $(n=10)$, lip $(n=8)$, palate $(n=6)$, retromolar trigone $(n=2)$, and combined sites $(n=1)$. Tumor staging was don according to the Tumor Nodular Metastasis (TNM) classification of the American Join Committee on Cancer (AJCC) into stages $(n=0)$, II $(n=15)$, III $(n=41)$, and IVA $(n=23)$ Patients with metastasis and those suffering from hypertension, diabetes, and infection were excluded from the study. All patients gave informed consent prior to their inclusion in the study, and the medical practitioner monitored the entire experiment. Studies were performed in accordance with the ethical standards of the institution.

The present study consisted of three groups. Group I consisted of OSSC patients $(n=79)$ and they were randomly divided into two groups, viz., II and III. Group II consisted of OSCC patients treated with RT $(n=48)$; and group III, OSCC patients treated with RT and simultaneously supplemented with a-tocophero $(\mathrm{RT}+\mathrm{AT})(n=31)$ during the entire period of radiotherapy. $\mathrm{RT}$ was given with a Telecobalt beam using anterior and lateral wedge pai or lateral parallel portals (Gammatron $-{ }^{60} \mathrm{CO}$ Theraton - $780-{ }^{60} \mathrm{CO}$; Phoenix $-{ }^{60} \mathrm{CO}$ ) at a dosage of $6000 \mathrm{cGy}$ in five fractions per week for a period of 6 weeks. a-tocopherol capsules (Bio-E capsules) were given at the dosage of 400 IU per day for 6 weeks from the first day of RT to the end of the treatment in RT + A patients. Oral intake of $a$-tocopherol is relatively 
safe at the dosage of $400 \mathrm{IU} /$ day for a period of 1 to 2 years. ${ }^{[7]}$

After overnight fasting, $5.0 \mathrm{ml}$ of each of the blood samples was collected in a test tube containing EDTA as an anticoagulant, before and after RT and after supplementation with a-tocopherol. Red blood cells (RBCs) hemolysates were used for the assay of malondialdehyde (MDA), ${ }^{[8]}$ SOD, ${ }^{[9]}$ catalase (CAT), ${ }^{[10]} \mathrm{GPx},{ }^{[11]} \mathrm{GR},{ }^{[12]} \mathrm{GST},{ }^{[13]}$ and glucose6-phosphate dehydrogenase (G6PD) ${ }^{[14]}$ by standard procedures. Chemicals used for this analysis were Analar grade, and fine chemicals were from Sigma Chemical Co., St. Louis, MO. The collection of patients' blood was approved by the human ethics committee of the hospital. The data were subjected to Students $t$ test.

\section{RESULTS}

The percentages of different demographic variables in patients with OSCC in this clinical study showed the ratio of men to women was 1.46 and the frequency of OSCC occurrence was in the age mean SD $50 \pm 12(95 \% \mathrm{Cl}$,
47.3-52.6\%) years. The occurrence of OSCC in cheek, floor of mouth was more predominant in women; whereas in men, the incidence in all the other sites was higher. The clinical staging of these patients revealed that $52 \%$ of patients were in stage III, 29\% in stage IVA, and 19\% in stage II. OSCC was more predominant in stage III patients, followed by stage IVA (without metastasis) patients. No metastatic patients were involved in this study. Most of the patients had well-differentiated carcinoma [Table 1].

The levels of MDA in hemolysate were significantly high $(P<0.001 ; 95 \% \mathrm{Cl}, 7.6-8.0 \%)$ in RT patients when compared to OSCC patients $(95 \% \mathrm{Cl}, 6.9-6.6 \%)$; whereas on vitamin $\mathrm{E}$ supplementation, the levels were significantly reduced $(P<0.001 ; 95 \% \mathrm{Cl}$, $5.4-5.8 \%$ ) in RT + AT patients when compared to RT patients [Figure 1]. The activities of SOD $(95 \% \mathrm{Cl}, 4.0-4.2 \%)$ and CAT $(95 \% \mathrm{Cl}$, $0.69-0.72 \%)$ were significantly decreased $(P<0.001)$ in RT patients as compared to OSCC patients (SOD: $95 \% \mathrm{Cl}, 5.31 \%$ to $5.33 \%$; CAT: $95 \% \mathrm{Cl}, 1.03-1.07 \%)$. The activities were significantly increased $(P<0.001$; SOD: 95\%

Table 1: Socio-demographic variables of OSCC in the study sample

\begin{tabular}{lccc}
\hline Demographic variables & Total $(n=79)$ & Male $(n=47)$ & Female $(n=32)$ \\
\hline $\begin{array}{l}\text { Age } \\
\text { Oral squamous cell cancer }(50 \pm 12 \text { year })\end{array}$ & 79 & 47 & 32 \\
Site of occurrence & & & \\
$\quad$ Cheek & $24(30)$ & $10(21)$ & $14(44)$ \\
Tongue & $15(19)$ & $11(23)$ & $4(12.5)$ \\
Alveolus & $13(16)$ & $9(19)$ & $4(12.5)$ \\
Floor of mouth & $10(13)$ & $4(9)$ & $6(19)$ \\
Lip & $8(10)$ & $7(15)$ & $1(3)$ \\
Palate & $6(8)$ & $4(9)$ & - \\
Retromolar trigone & $2(3)$ & $2(4)$ & $1(3)$ \\
Combined sites & $1(1)$ & - & - \\
Stages & - & - & $7(22)$ \\
Stage I & $15(19)$ & $8(17)$ & $14(44)$ \\
Stage II & $41(52)$ & $27(57)$ & $11(34)$ \\
Stage III & $23(29)$ & $12(26)$ & \\
Stage IVA & & &
\end{tabular}

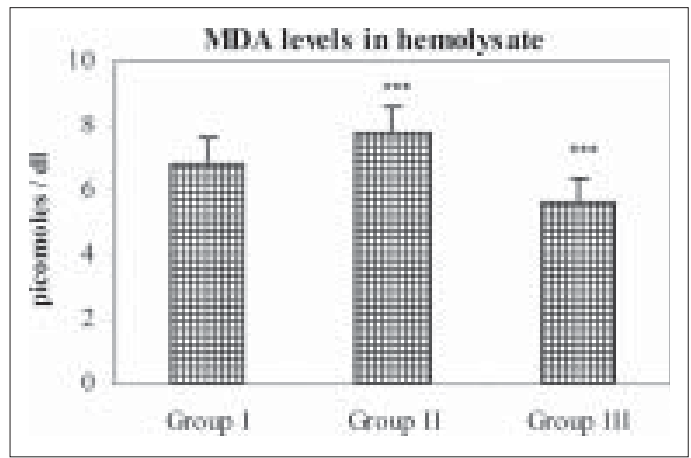

Figure 1: Levels of malondialdehyde in the hemolysate of experimental groups. Values are expressed as mean \pm SD. A statistically significant value of Group II was compared with that of Group I, and that of Group III was compared with that of Group II. ${ }^{* \star *} P<0.001$.

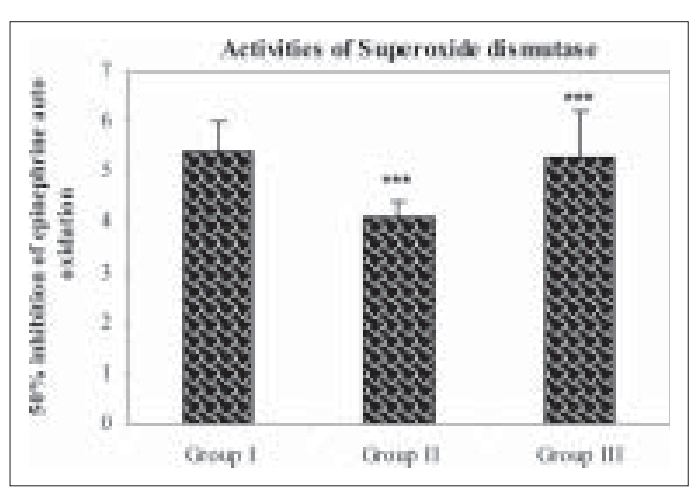

Figure 2: Activity of superoxide dismutase in the hemolysate of experimental groups. Values are expressed as mean $\pm \mathrm{SD}$. A statistically significant value of Group II was compared with that of Group I, and that of Group III was compared with that of Group II. ${ }^{* * *} P<0.001$.

Cl, $4.98-5.6 \%$; CAT: $95 \% \mathrm{Cl}, 1.04-1.13 \%)$ in RT + AT patients when compared to RT patients [Figures 2 and 3 ].

A significant decrease in the activities of glutathione-dependent enzymes - GST $(P<0.001 ; 95 \% \mathrm{Cl}, 0.62-0.66 \%)$, GPX

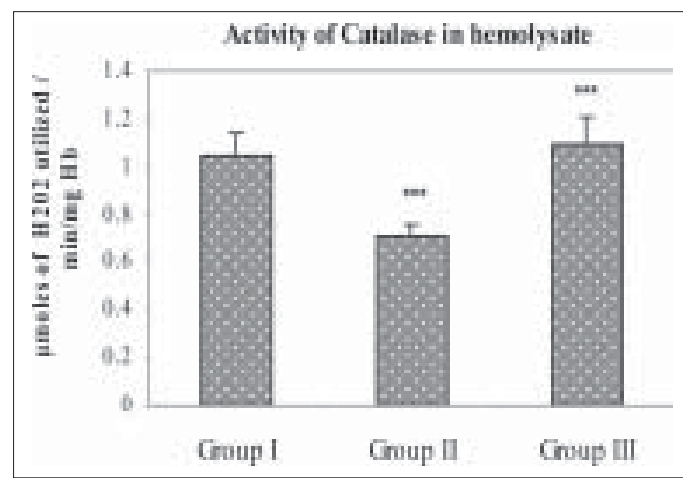

Figure 3: Activity of catalase in the hemolysate of experimental groups. Values are expressed as mean \pm SD. A statistically significant value of Group II was compared with that of Group II. ${ }^{* * \star} P<0.001$.

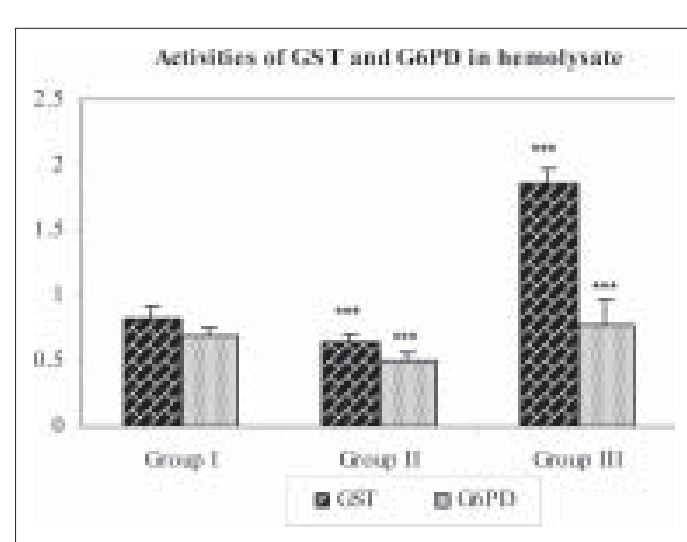

Figure 4: Activities of glutathione S-transferase and glucose 6-phosphate dehydrogenase in the hemolysate of experimental groups. Values are expressed as mean \pm SD. A statistically significant value of Group II was compared with that of Group I, and that of Group III was compared with that of Group II. ${ }^{* * *} P<0.001$. GST - $\mu$ moles of CDNB conjugated/min/mg Hb; G6PD - units/mg Hb

$(P<0.001 ; 95 \% \mathrm{Cl}, 4.8-5.3 \%)$, G6PD $(P<0.001 ; 95 \% \mathrm{Cl}, 0.48-0.52 \%)$, and $\mathrm{GR}$ $(P<0.05$; DF $1.176 ; 95 \% \mathrm{Cl}, 1.2-1.4 \%)$ - was noted in RT patients when compared to OSCC patients (GST: $95 \% \mathrm{Cl}, 0.81-0.85 \%$; GPx: 95\% Cl, 6.5-7.5\%; G6PD: 95\% Cl, 0.67-0.71\%; GR $95 \% \mathrm{Cl}, 1.3-1.5 \%$ ); whereas increased activities 
of GST $(P<0.001 ; 95 \% \mathrm{Cl}, 1.82-1.89 \%)$, GPx $(P<0.001 ; 95 \% \mathrm{Cl}, 7.6-8.8 \%)$, G6PD $(P<0.001 ; 95 \% \mathrm{Cl}, 0.71-0.85 \%)$, and $\mathrm{GR}$ $(P>0.05$; DF $2.275 ; 95 \% \mathrm{Cl}, 1.34-1.6 \%)$ were observed in RT + AT patients when compared to RT patients [Figures 4 and 5].

\section{DISCUSSION}

Lipid peroxidation is a free radical-mediated process. It is involved in the formation of lipid radicals, a re-arrangement of the unsaturated lipids that results in a variety of degraded products like alkanes, MDA, conjugated dienes, lipid hydroperoxides; and eventually destruction of membrane lipids, ${ }^{[15]}$ and modulates membrane-bound ATPases. ${ }^{[16]}$

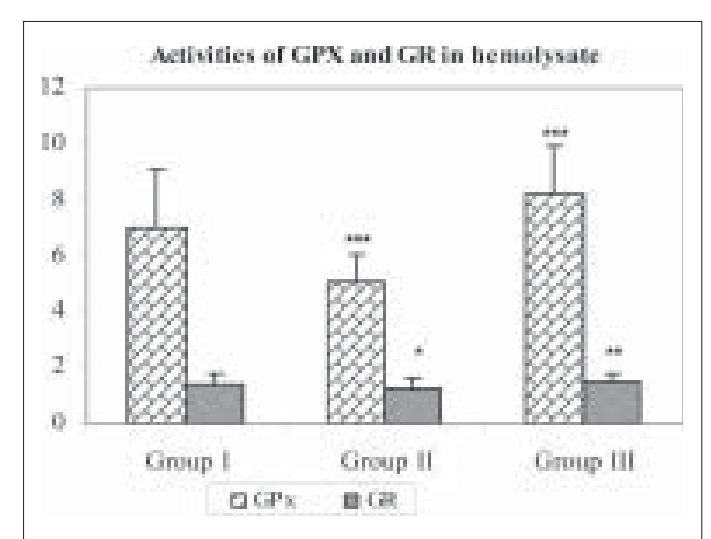

Figure 5: Activities of glutathione peroxidase and glutathione reductase in the hemolysate of experimental groups. Values are expressed as mean \pm SD. A statistically significant value of Group II was compared with that of Group I, and that of Group III was compared with that of Group II. ${ }^{*} P<0.05$ (degree of freedom, 1.76); ${ }^{* *} P<0.05$ (degree of freedom, 2.275); ${ }^{* *} P<0.001$. Group I: oral squamous cell carcinoma patients (GPx: $95 \% \mathrm{Cl}$, 6.5-7.5\%; GR: $95 \% \mathrm{Cl}, 1.3-1.5 \%$ ); Group II: oral squamous cell carcinoma patients treated with radiotherapy (GPx: 95\% Cl, 4.8-5.3\%; GR: $95 \% \mathrm{Cl}, 1.2-1.4 \%$ ); Group III: oral squamous cell carcinoma patients treated with radiotherapy and simultaneously supplemented with a-tocopherol (GPx: 95\% Cl, 7.6-8.8\%; GR: $95 \% \mathrm{Cl}$, 1.34-1.6\%). GPX - $\mu$ moles of GSH oxidized $/ \mathrm{min} / \mathrm{mg} \mathrm{Hb}$; GR - $\mu$ moles of $\mathrm{NADPH}$ oxidized $/ \mathrm{min} / \mathrm{mg} \mathrm{Hb}$ )
The increased levels of MDA in RBCs of RT patients can be attributed largely to higher rate of lipid peroxidation. Radiation-induced free radicals produce peroxidation of lipids, leading to structural and functional damage to cellular membranes. RBC membranes are more prone to lipid peroxidation because of their high polyunsaturated lipid content and direct exposure to molecular oxygen and hemoglobin. ${ }^{[17,18]}$ The reduction to compensate the increased lipid peroxidation by radiation due to fall in total radical-trapping capacity of blood plasma and marked reduction in plasma levels of antioxidants such as vitamins $\mathrm{E}, \mathrm{C}, \beta$-carotene, and GSH during RT (data not shown) result in elevation of lipid peroxidation products.

In RT + AT patients, lower levels of MDA were observed. The reduction may be due to protective effect of a-tocopherol on cell membrane lipids and unsaturated fatty acids (UFAs) against oxidative degradation. Inhibition of oxidation of membrane components occurs by blocking the free-radical peroxidation process, the main targets of which are UFAs. ${ }^{[19]} a-$ tocopherol is considerably more lipophilic and a potent antioxidant. Penetration to a precise site in the membrane may be an important feature of the protection against highly reactive radicals. As a-tocopherol is a major lipid phase antioxidant, it confers protection against oxidative lipid damage in RBC membrane of RT + AT patients. Although in biological membranes, a-tocopherol is present in a low molar ratio compared to the abundance of phospholipids that are highly susceptible to oxidative damage, it confers protection to membrane against lipid peroxidation both enzymatically and non-enzymatically (data not shown). Supportive nutritional therapy with antioxidants during $\mathrm{RT}$ reduces the generation of lipid peroxides that results from the treatment. ${ }^{[20]}$ Several dietary supplements containing vitamins also play a significant role in this matter. The present results strongly favored the protective role of a-tocopherol, which was evident from significant reduction in lipid peroxide levels.

The lowered activities of SOD and CAT in RT patients may have been due to inactivation of both these enzymes by the singlet oxygen generated by radiation. ${ }^{[21]}$ Furthermore, the toxic oxygen radicals may react with intrinsic or extrinsic radical scavenger, forming a secondary free radical that by itself can produce injury. ${ }^{[22]}$ SOD reacts with superoxide radicals and converts them to hydrogen peroxide; excessive amounts of these metabolites start lethal chain reactions, which oxidize and disable structures that are required for cellular integrity and survival. ${ }^{[23]}$ Tumor cells have increased rates of metabolism compared with normal cells, which would typically lead to increased number of reactive oxygen species. The reduced activities of both the enzymes in red cell might be due to abnormalities in the regulation of SOD and CAT genes in the pluripotent stem cells; ${ }^{[24]}$ alternatively, it could be due to posttranslational modification of the enzymes by free radicals. ${ }^{[25]} \mathrm{RBC}$ are more susceptible to superoxide radical, so the increased exposures of circulating RBCs to superoxide generated by cancer cells damage the RBCs. Decreases in SOD and CAT were also observed in RBCs of CMF-treated breast cancer patients. ${ }^{[26]} \mathrm{RT}+\mathrm{AT}$ patients showed increased activity of SOD; this might be due to protective effect of a-tocopherol on RBCs. Retention of normal RBC function might have resulted in normal activities of SOD, which facilitates the removal of superoxide anions produced by radiation. Addition of a-tocopherol in vitro enhances the activity of SOD in rabbits. ${ }^{[27]}$

Human erythrocytes are rich in GSH and GPx. GSH acts as a substrate or cofactor for the antioxidant enzymes GPx, GST, and GR, which are involved in the termination of peroxidation, by removing peroxides generated within the cell. The three enzymes GPx, GR, and G6PD act in consort, with G6PD supplying reducing equivalent needed for GR activity which in turn maintains adequate concentration of GSH required for GPx activity. GPx removes $\mathrm{H}_{2} \mathrm{O}_{2}$, one of the powerful mediators of oxidative stress. ${ }^{[28]}$ GPx plays a critical role in maintaining the redox status during acute oxidative stress. This protective role of GPx is coordinated with other antioxidant enzymes. ${ }^{[29]}$

The utilization of GSH may be mediated by GS or GPx system. Unavailability of GSH, causing a reduction in the activity of GPx and GST, has been reported. GST also possesses peroxidase activity and can directly attack the peroxides. ${ }^{[30}$ The activities of GSH-dependent enzymes [GST, GPx, G6PD, and GR (nonsignificant)] were lowered in RT patients when compared to OSCC patients. Significant decreases in the activities of antioxidant enzymes have been studied in radiation-induced Swiss mice. ${ }^{[31]}$ The erythrocyte GSH-related enzyme activity and radiation response were studied by others. ${ }^{[6,32]}$ In intact and healthy cells, the enzymes are restored immediately after each interaction. In the case of RT patients, norma synthesis/repair is disrupted due to damage in DNA and membranes. ${ }^{[33]}$ The slow recovery in the activity of antioxidant enzymes in RT could be due to the lack of antioxidant enzymes. RT + AT patients showed an improvement in 
their activities, which might be due to the fact that a-tocopherol improves the red cell survival in patients with GSH synthetase deficiency and increases red cell GPx and GST activities. ${ }^{[34]}$ Improvement of RBCs by a-tocopherol in RT + AT patients may have restored the activities.

The present findings suggest that radiotherapy causes increased MDA levels and concomitant decrease in the activities of SOD, CAT, and GSH-dependent enzymes which arise as a result of enormous production of free radicals in the system of radiation-treated OSCC patients. a-tocopherol supplementation improves the oxidant-antioxidant enzymes status and thereby protects the erythrocytes from free radical damage during radiotherapy.

\section{ACKNOWLEDGMENT}

Soruce of Support given in page No. 148, right side column end.

\section{REFERENCES}

1. Parkin DM, Pisani P, Ferlay T. Estimates of the worldwide incidence of eighteen major cancer in 1985. Int J Cancer 1993;54:594-606.

2. Johnson NW. Orofacial neoplasms: Global epidemiology, risk factors and recommendations for research. Int Dent J 1991;41:365-75.

3. Veninga TS. Implications of bioamines in the x-ray temperature response of cats and rabbits. Radiat Res 1971;48:358-67.

4. Streffer C, Van Beuningen D. Recent results in cancer research. In: Streffer C, editor. Hyperthermia and the therapy of malignant tumors. $1^{\text {st }}$ ed. Berlin: V Springer; 1987. p. 24-7. 5. Sabitha KE, Shymala Devi CS. Oxidant and antioxidant activity changes in patients with oral cancer and treated with radiotherapy. Eur $\mathrm{J}$ Cancer B Oral Oncol 1999;35:273-7.

6. Dean RJ, Cheeseman KH. Vitamin E protects proteins against free radical damage in lipid environments. Biochem Biophys Res Commun 1987;148:1277-82.

7. Vatassery GT, Raver T, Dysken M. High doses of vitamin $\mathrm{E}$ in the treatment of disorders of the central nervous system in the aged. Am J Clin Nutr 1999;70:793-801.

8. Okhawa H, Onishi N, Yagi K. Assay of lipid peroxidation in animal tissue by thiobarbituric acid reaction. Anal Biochem 1970;95:351-8.

9. Misra HP, Fridovich I. The role of superoxide anion in the autoxidation of epinephrine and a simple assay for superoxide dismutase. J Biol Chem 1972;247:3170-5.

10. Sinha AK. Colorimetric assay of catalase. Anal Biochem 1972;47:389-94.

11. Rotruck TJ, Pope AL, Ganther HE. Selenium: biochemical role as a component of glutathione peroxidase, purification and assay. Science 1973;179:588-90.

12. Carlberg MB. Glutathione levels in rat brain. J Biol Chem 1975;250:5475-80.

13. Habig WH. Jackobyus B. Glutathione-Stransferase: The first enzymatic step in mercapturic acid formation. J Biol Chem 1981;249:7130-9.

14. Baquer NJ, McLean P. Evidences for the existence and functional activity of pentose phosphate pathway enzymes in the large particle fraction isolate from rat tissues. Biochem Biophys Res Commun 1972;46:167-74.

15. Upasani CD, Khera A, Balaraman R. Effect of lead with vitamin $\mathrm{E}, \mathrm{C}$ or spirulina on malondialdehyde, conjugated dienes and hydroperoxides in rats. Indian J Exp Biol 2001;39:70-4.

16. Sridevi N, Venkatraman $P$, Senthil Kumar K, Krishnamoorthi G, Arunakaran J. Oxidative stress modulates membrane-bound ATPases in brain regions of PCB (Aroclor 1254) exposed rats:protective role of a -Tocopherol. Biomed
Pharmaco Ther 2007;17:459-69.

17. Subramaniam $S$, Shyama $S$, Jagadeesan $M$, Shyamala Devi CS. Oxidant and antioxidant levels in the erythrocyte of breast cancer patients treated with CMF. Med Sci Res 1993;21:79-80.

18. Srivastava DSL, Mittal RD. Free radical injury and antioxidant status in patients with benign prostate hyperplasia and prostate cancer. Indian J Clin Biochem 2005;20:162-5.

19. Clemens MR, Waladkhani AR, Bublitz K, Ehniger G, Gey KF. Supplementation with antioxidants prior to bone marrow transplantation. Wien Klin Wochenschr 1997;109:771-6.

20. Bipin Kumar, Mitra NJ, William CC, Joel SB Dphil, Kedar NP. D- alpha-tocopheryl Succinate (vitamin E) enhances radiation-induced chromosomal damage levels in humal cancer cells, but reduces it in normal cells. J Am Coll Nutr 2002;21:339-43.

21. Sherman M. Antioxidant decade. Pharm Times 2000;66:69.

22. Escobar JA, Rubio MA, Lissi EA. Superoxide dismutase and catalase inactivation by singlet oxygen and peroxyl radicals. Free Radic Biol Med 1996;20:285-90.

23. Sampson JB, Beekman JS. Hydrogen peroxide damages the zinc-binding site of zinc-deficient $\mathrm{Cu}$ $\mathrm{Zn}$ superoxide dismutase. Arch Biochem Biophys 2001;392:8-13

24. Fridovich I. Superoxide dismutases. Annu Rev Biochem 1975;44:147-52.

25. Gonzales R, Auclair C, Voisin E, Gantero H, Dhemy D, Biovin P. Superoxide dismutase, catalase and glutathione peroxidase in red blood cells from patients with malignant diseases. Cancer Res 1984:44:4137-9.

26. Corrons V, Pujades MA, Scieria Ribera JM. Characteristics of red cell pyruvate kinase $(\mathrm{PK})$ and pyrimidine $5^{\prime}$-nucleotidase (p5N) abnormalities in acute leukaemia and chronic lymphoid diseases with leukaemic expression Br J Haemotol 1987;66:173-7.

27. Subramaniam S, Shyama S, Shyamala Devi CS. Erythrocyte antioxidant enzyme activity in CMF treated breast cancer patients. Cancer Biochem Biophys 1994;14:177-82.

28. Halliwell B, Gutteridge JM. Free radicals in biology and medicine, Oxford: Clarendon Press; 1989.

29. Cheng W, Fu Y, Porres J, Ross D, Lei X. Selenium dependent cellular glutathione peroxidase protects mice against a pro-oxidant induced oxidation of NADPH, NADH, lipids and proteins. FASEB J 1999;13:1467-75.

30. Mari M, Cederbaum Al. Induction of catalase, alpha and microsomal glutathione S-transferase in CYP2E1 over expressing HePG2 cells and protection against short-term oxidative stress. Hepatol 2001;33:652-61.

31. Mukundan $\mathrm{H}$, Bahadur AK. Glutathione leve and its relation to radiation therapy in patients with cancer of uterine cervix. Indian J Exp Bio 1999;37:859-64.

32. Uma Devi P, Ganasoundari A. Modulation of glutathione and antioxidant enzymes of Ocimum sanctum and its role in protecting against radiation injury. Indian J Exp Biol 1999;37:262-8.

33. Breimer LH. Molecular mechanisms of oxygen radical carcinogenesis and mutagenesis: The role of DNA base damage. Mol Carcinog 1990;3:188-97.

34. Ozkan A, Fiskin K, Ayhan AG. Effect of vitami $E$ and selenium on antioxidant enzymes in brain kidney and liver of cigarette smoke-exposed mice. Biologia 2007;62:360-4.

Source of Support: The Indian Council for Medical Research, New Delhi, Conflict of Interest: None declared. 